\title{
OPEN Performance and host association of spotted lanternfly (Lycorma delicatula) among common woody ornamentals
}

\author{
Osariyekemwen Uyi ${ }^{1,2}$, Joseph A. Keller ${ }^{1}$, Emelie Swackhamer ${ }^{3}$ \& Kelli Hoover ${ }^{1 \bowtie}$
}

Lycorma delicatula (spotted lanternfly) has a broad host range with a strong preference for the invasive host plant from its native range, tree of heaven (Ailanthus altissima); it had long been speculated that $L$. delicatula could not develop or reproduce without access to tree of heaven. In 2019, we found that this assumption was incorrect, but fitness was reduced in the absence of $A$. altissima in that the number of egg masses laid was dramatically fewer for insects reared on suitable non- $A$. altissima host plants that had recently been established. We hypothesized that longer established, larger trees (of the same species) would improve the fitness of $L$. delicatula in the absence of tree of heaven. In spring 2020, we examined insect performance with and without access to $A$. altissima by tracking development, survival, host tree association and oviposition in large enclosures with trees planted two years prior to the study. Each enclosure included one each of Juglans nigra, Salix babylonica and Acer saccharinum along with either one A. altissima or one Betula nigra; these trees had twice the diameter of the same trees the previous year. We reared nymphs with and without access to $A$. altissima, released them into the corresponding large enclosures as third instars, and monitored them from early July 2020 through November 2020. We also determined whether lack of access to $A$. altissima by parents of $L$. delicatula have any fitness effects on offspring performance. To ensure adequate adult populations for comparing fecundity between treatments, third instars were released into the multi-tree enclosures due to high mortality in earlier instars that occurred in a similar study in 2019. Insect survival was higher and development faster with access to $A$. altissima. Third and fourth instar nymphs were most frequently observed on $A$. altissima when it was present, while adults were equally associated with $A$. saccharinum and $A$. altissima. In the absence of $A$. altissima, nymphs were most frequently found on $S$. babylonica, while adults were most often on $A$. saccharinum. Females with access to $A$. altissima deposited nearly 7 -fold more egg masses than those without access to $A$. altissima, which is consistent with the difference in egg mass numbers between the two treatments the previous year; thus, our hypothesis was rejected. The offspring of parents that had been reared without access to $A$. altissima showed similar survival and development time from egg to adult as offspring from parents that never had access to $A$. altissima. These findings suggest that managers need to be aware that even in the absence of $A$. altissima in the landscape, several hardwood host trees can be utilized by $L$. delicatula to develop and reproduce, but fitness without $A$. altissima is likely to still be reduced.

Since 2014, the spotted lanternfly (SLF), Lycorma delicatula (White) (Hemiptera: Fulgoridae), an exotic planthopper, has invaded nine states in the Northeast, mid-West, and mid-Atlantic regions of the U.S. Native to China, Taiwan and Vietnam, L. delicatula has also expanded its range to include South Korea and Japan ${ }^{1-4}$. Following its initial detection in Berks County, Pennsylvania ${ }^{1}$, L. delicatula has spread to New Jersey, New York, Virginia, Maryland, Delaware, West Virginia, Connecticut, and Ohio ${ }^{4,5}$. The invasion success of this pest may be partly due to its broad host range ${ }^{2}$, apparent capacity for dispersal ${ }^{6,7}$ and its potential to occupy a wide range of climatic

${ }^{1}$ Department of Entomology, Pennsylvania State University, 501 ASI Building, University Park, PA 16802, USA. ${ }^{2}$ Department of Animal and Environmental Biology, University of Benin, P.M.B. 1154, Benin City, Nigeria. ${ }^{3}$ Horticulture Educator, Penn State Extension Montgomery, Collegeville, PA 19426, USA. ${ }^{\varpi}$ email: kxh25@ psu.edu 

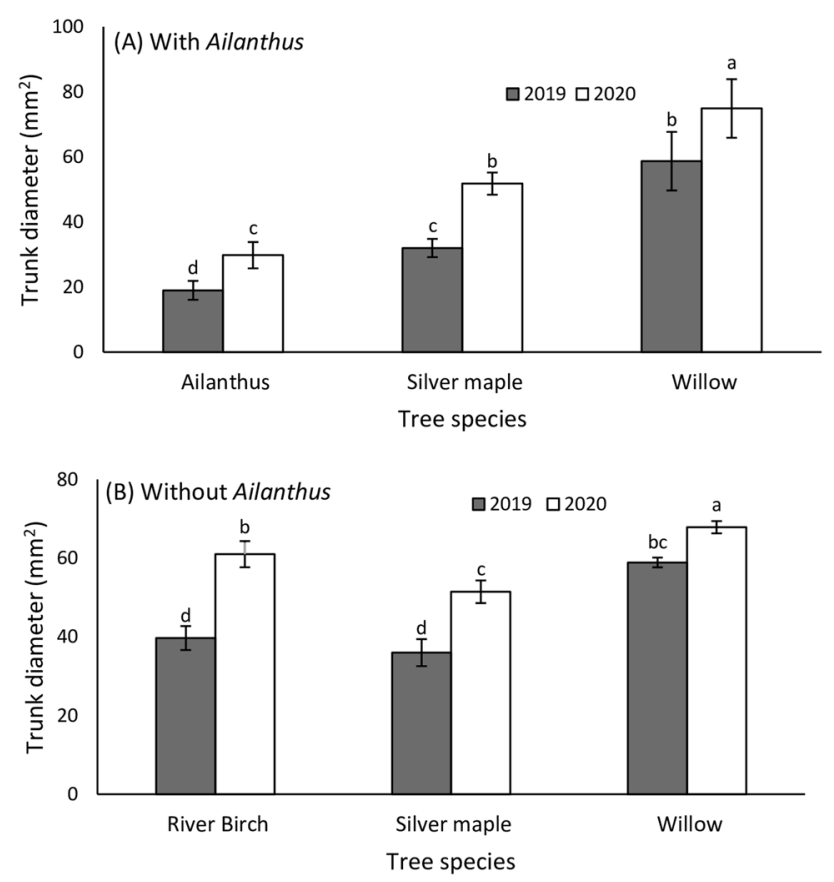

Figure 1. Mean $( \pm \mathrm{SE})$ trunk diameter $(\mathrm{mm})$ of tree species in enclosures with Ailanthus $(\mathrm{A})$ and without Ailanthus (B) ( $n=5$ enclosures) in 2019 and 2020. Measurements were made on October 31, 2019 and November 3, 2020. Means within a column followed by different letters are significantly different (Bonferroni post hoc test: $P<0.05)$. Black walnut trees were not included in the analysis because most died during the 2019 studies and had to be replaced in spring of 2020.

conditions and ecosystems, especially disturbed habitats where the preferred host Ailanthus altissima (Mill.) Swingle (Simaroubaceae) (tree-of-heaven) is abundant ${ }^{3,8,9}$.

As a generalist phloem sap feeder, L. delicatula has proven to be a prominent pest in forest and agricultural ecosystems and a nuisance pest in suburban landscapes, causing significant economic losses to vineyards, nurseries, and sawmills in the invaded regions ${ }^{4,10}$. For the ornamentals and forest products industries, the major economic impacts are primarily due to the cost of best management practices to comply with quarantine restrictions, and in some cases, reduced sales ${ }^{10,11}$. Lycorma delicatula is projected to cause $\$ 42.6$ million in damages annually if it spreads across Pennsylvania ${ }^{11}$. Although studies on the impacts of feeding by L. delicatula on host plant health are in their infancy, phloem feeding by nymphs and adults is known to cause physiological stress in young stems that may in turn cause infested branches to wilt, lose vigor or die following heavy infestations ${ }^{10,12}$. Feeding by $L$. delicatula results in the production of copious amounts of honeydew, which promotes the growth of sooty mold on plants below feeding sites, impeding photosynthesis of affected plants ${ }^{13-16}$. Damage caused by $L$. delicatula decreases grapevine growth, reducing crop yield by up to $90 \%$ and sometimes killing the vines (Vitis spp. L. [Vitales: Vitaceae] ${ }^{10,12}$. Additionally, L. delicatula poses a threat to the growth of several hardwood trees, including silver maple (Acer saccharinum L. [Sapindaceae]), red maple (A. rubrum L. [Sapindaceae]), black walnut (Juglans nigra L. [Juglandaceae]), weeping willow (Salix babylonica L. [Salicaceae]), river birch (Betula nigra L. [Betulaceae]) and tulip tree (Liriodendron tulipifera L. [Magnoliaceae]) $)^{1,2,17-19}$.

Lycorma delicatula prefers A. altissima in both its native and invasive ranges, though it can utilize over 103 plant species across 33 families ${ }^{4,17,18}$. In North America, feeding has been observed on 56 plant species, which include native, cultivated, and nonnative species ${ }^{18}$. The rapid spread of this pest is likely facilitated by the prevalence of $A$. altissima, in addition to other suitable host plant species ${ }^{18}$. Despite the broad host range of $L$. delicatula, not much is known about its host preferences and relative performance when feeding on common woody ornamentals but Murman et al. ${ }^{20}$ reported that eight species were able to support the development of L. delicatula from first instars to adulthood. Our previous study in $2019^{19}$ showed that this pest can complete development and reproduce on young weeping willow (S. babylonica), silver maple (A. saccharinum L) and river birch (B. nigra) without access to $A$. altissima. But, development from egg to adult was delayed by one week and the number of egg masses laid by females was significantly fewer (6.7-fold) in enclosures with no access to A. altissima. We hypothesized however, that $L$. delicatula without access to A. altissima can develop and produce as many eggs as those with access to A. altissima if provided trees that have been established longer and are bigger than the trees they fed on in the previous year. As a voracious sap feeder, L. delicatula appears to prefer larger trees as an adult (personal observations). Thus, in 2020, we investigated the fitness and host association of L. delicatula among planted common woody ornamentals using trees that were 2-fold larger in diameter in 2020 than in 2019 (see tree size measurement details in "Materials and methods" section, Fig. 1.). A further objective of this study was to determine whether offspring ( $\mathrm{F}_{1}$ generation) from parents that were reared from egg to adult without access to $A$. altissima suffer any lingering fitness effects as they develop into adults. 


\section{Materials and methods}

Origin and maintenance of trees and insect cultures. In Macungie, Berks County, PA, we set up ten $5.76 \mathrm{~m}^{2}$ plots in mid-September 2018; five plots each were randomly allocated to two treatments: 'with Ailanthus' and 'without Ailanthus' ${ }^{\text {'. }}$. All plots contained one S. babylonica, one A. saccharinum, and one J. nigra spaced $1 \mathrm{~m}$ apart; in addition, the 'with Ailanthus' plots were also planted with one A. altissima, while the 'without Ailanthus' plots contained one river birch (B. nigra) in place of A. altissima. We purchased the Salix babylonica and B. nigra as 15-gallon potted trees ( $200 \mathrm{~cm}$ tall) at New Hanover Gardens (Perkiomenville, PA), and A. saccharinum as 7-gallon $(\sim 150 \mathrm{~cm}$ tall $)$ and $J$. nigra as 2 -gallon $(\sim 90 \mathrm{~cm}$ tall) trees from Octoraro Native Plant Nursery (Kirk, PA). Since A. altissima is a ubiquitous invasive plant, small trees $(\sim 90 \mathrm{~cm}$ tall $)$ were dug up and transplanted from a local property with the owner's permission. We selected these species because they are common in this region of the U.S. and are often used as hosts trees by L. delicatula in Pennsylvania. Lycorma delicatula were confined to each plot using a rectangular screen enclosure made of PAK25 Anti-Insect Mesh (Hummert International, MO) attached to a frame $(3 \times 2.4 \times 2.4 \mathrm{~m})$ made of galvanized steel tubes $(38 \mathrm{~mm}$ diameter $)$ at each corner to prevent collapse during windy thunderstorms. To obtain access to each enclosure we installed a $1.8 \mathrm{~m}$ zipper on one side. To prevent $L$. delicatula nymphs or adults from escaping from the enclosures, sandbags $(7.6 \times 99 \mathrm{~cm})$ were sewn into the bottom edge of the enclosure to weigh down the sides. We installed drip irrigation connected to the well on the property. In the early spring, trees were pruned to minimize crowding.

In January 2020, egg masses of $L$. delicatula were field collected in Allentown, PA and kept in two pop-up cages $(90 \times 60 \times 60 \mathrm{~cm})$ under ambient environmental conditions in an unheated greenhouse in Macungie, PA. In early May, egg masses were transferred to 20 pop-up cages $(90 \times 60 \times 60 \mathrm{~cm})$ containing potted host plants and housed under a canopy at the experimental site. Here, the pop-up cages were used for rearing newly hatched nymphs until they reached the third instar. In this way, all plants received direct sunlight for part, but not all, of the day. These pop-up cages were divided between two treatments: 'with Ailanthus' (10 cages) and 'without Ailanthus' (10 cages). Pop-up cages 'with Ailanthus' contained one potted $\sim 60 \mathrm{~cm}$ tall A. altissima (planted from field-collected seeds), one potted $\sim 45 \mathrm{~cm}$ tall V. vinifera (cv. Cabernet-Franc; Hermann J. Wiemer Vineyard, Dundee, NY), one potted $\sim 45 \mathrm{~cm}$ tall strawberry and one potted $\sim 45 \mathrm{~cm}$ tall sunflower, while pop-up cages 'without Ailanthus' contained one potted $\sim 45 \mathrm{~cm}$ tall V. vinifera, one strawberry and one sunflower. Neonates in both treatments were reared to third instar until release into each multi-tree enclosure.

Experiment I: Lycorma delicatula survival, development and host plant associations. Between July 7 and July 10, 2020, 120 one- to three-day old third instars were released into each multi-tree enclosure. Enclosures 'with Ailanthus' received nymphs with prior access to A. altissima from the pop-up cages with potted A. altissima (see details above) and vice versa ${ }^{19}$. To maximize the availability of adults for comparing fecundity between the two treatments, we released third instars into the enclosures to avoid the early instar mortality evident in our 2019 study $^{19}$ in which we found that L. delicatula can be reared from first instar to adult without access to A. altissima. Each week we monitored plots for survival, life stage, and which host tree the insects were found on by counting the numbers of nymphs (from July 15, 2020 to September 2, 2020) and adults (August 12, 2020 to November 4, 2020) present or seen on each host tree species and on other surfaces in each enclosure. After reaching adulthood we placed wooden planks and red maple logs in the enclosures to provide additional oviposition material and began monitoring and recording for oviposition weekly through November 4, 2020 when a hard freeze killed all remaining adults. To document growth between 2019 and 2020, trunk diameter measurements were made on October 31, 2019 and November 3, 2020, and we compared trunk diameter of trees by species between 2019 and 2020. Trunk diameter measurements for J. nigra were not available because most of these trees had died during the 2019 studies and were replaced in spring of 2020. For both treatments, trunk diameter differed significantly by year ('with Ailanthus': $F_{1,29}=79.27 ; P=0.0001$; 'without Ailanthus': $F_{1,29}=40.84 ; P=0.0001$ ) and tree species ('with Ailanthus': $F_{2,29}=45.47 ; P=0.0001$; 'without Ailanthus': $F_{2,29}=101.87 ; P=0.0001$ ). There were no significant tree species $\times$ year interactions ('with Ailanthus': $F_{2,29}=1.15$; $P=0.334$; 'without Ailanthus': $\left.F_{2,29}=2.25 ; P=0.070\right)$. Trees used in 2020 were on average $26.0 \pm 2.3 \%$ larger than the same trees were in 2019 (Fig. 1A,B).

Experiment II: Performance of $\boldsymbol{L}$. delicatula offspring. To compare fitness of offspring from parents that did or did not have access to A. altissima trees during development from egg to adult, we collected egg masses from the prior experiment (as above) conducted in $2019^{19}$. In early-June of 2020 these egg masses were carefully collected from the trees in each multi-tree plot, placed in Petri dishes and held in pop-up cages $(90 \times 60 \times 60 \mathrm{~cm})$ containing two potted $\sim 60 \mathrm{~cm}$ tall A. altissima trees (planted from seeds), with 4 replicates per treatment. Here, the pop-up cages were used to rear the newly hatched nymphs until adult emergence. All pop-up cages were placed in open field conditions in the same location but were sheltered from direct rainfall. Trees were watered thrice per week and replaced once per month with fresh potted A. altissima trees. Weekly, we recorded survival and development of $L$. delicatula by counting the numbers of nymphs and adults present and seen in each cage.

Statistical analysis. To evaluate the effect of the presence or absence of A. altissima on the survival of $L$. delicatula in Experiments I and II, we fit a generalized linear mixed model with a binomial error distribution and logit link function using the $g \operatorname{lmm} T M B$ function ${ }^{19}$ in $\mathrm{R}^{21,22}$. Our model included treatment, date of observation, and the interaction between these two factors as predictors, and cage as a random effect to account for repeated observations. Similarly, to assess the effect of A. altissima presence on the timing at which individuals reached the fourth instar and adulthood in Experiments I and II, we fit a GLM mixed effects model with a binomial error distribution and a logit link function. We predicted the proportion of individuals in each cage that had reached 


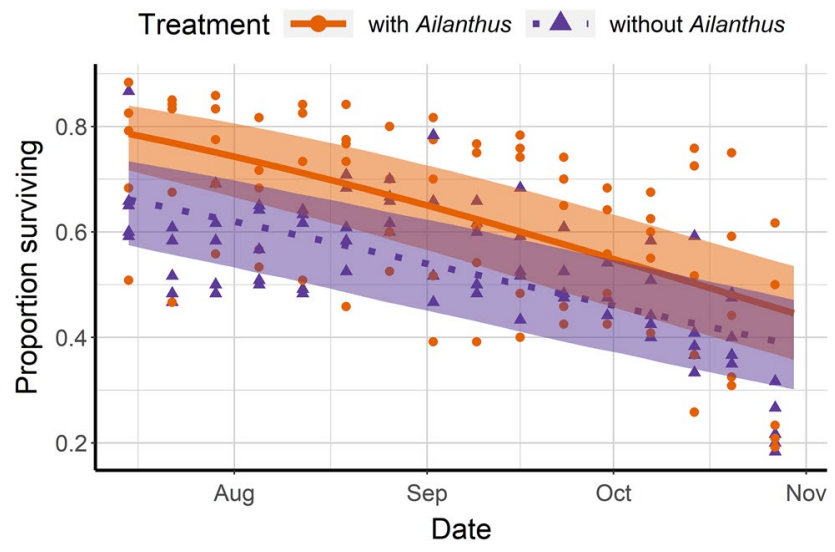

Figure 2. Proportion of Lycorma delicatula (nymphs and adults combined) that survived in enclosures with planted Ailanthus altissima, Acer saccharinum, Juglans nigra and Salix babylonica ('Ailanthus', $n=5$ enclosures) or enclosures with the same tree species except for the presence of Betula nigra in place of A. altissima ('without Ailanthus, $n=5$ enclosures) from July 15 to November 4, 2020. Fitted binomial regression lines are shown, with shaded areas indicating 95\% confidence intervals for predicted regression means. In total, 120 third-instar nymphs were released in each enclosure and their numbers and host tree associations were recorded weekly.

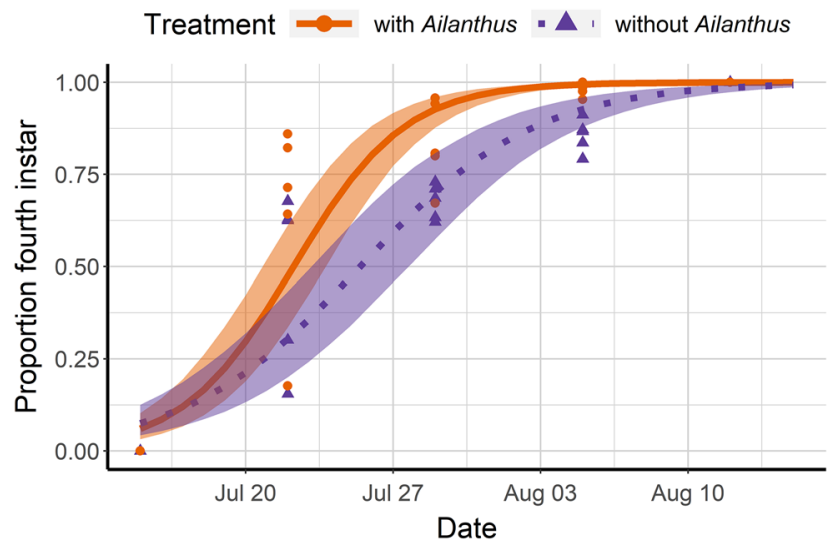

Figure 3. Proportion of L. delicatula that developed from the third to the fourth instar over time, with fitted logistic regression lines, in enclosures with and without Ailanthus altissima.

the fourth instar and adult stages based on the date, treatment (with or without A. altissima) and interaction of these two factors. We again included cage as a random effect in the model to account for repeated observations. We assessed the significance of the treatment by conducting a likelihood ratio test to compare the full model against a reduced model, excluding treatment as a predictor. Repeated measures GLM ANOVA was used to compare the host plant association (i.e., the proportion of nymphs and adults of L. delicatula on a given tree species) of L. delicatula in the presence or absence of $A$. altissima using SPSS version 20.0 (IBM, SPSS Inc. Chicago, IL). If the overall model was significant, differences between trees was determined using the Bonferroni post hoc test. The Mann Whitney U test was used to compare the number of eggs masses between treatments using SPSS version 20.0. Juglans nigra trees were not included in the analysis because most died during the 2019 studies and had to be replaced in spring of 2020 .

IUCN policy statement. Collection of plant material was done in compliance with relevant institutional, national, and international guidelines and legislation.

\section{Results}

Survival, development time, host association and egg mass count. Following release into multitree enclosures, the proportion of individuals of $L$. delicatula (from third instar nymph to adult) that survived was approximately $10 \%$ higher in enclosures with A. altissima compared to the non-Ailanthus enclosures throughout the season $\left(\chi^{2}=16.29, \mathrm{df}=1, P=0.001\right.$; Fig. 2$)$. Third instar nymphs in A. altissima enclosures developed slightly faster to fourth instar $\left(\chi^{2}=56.26, \mathrm{df}=1, P=0.001\right.$; Fig. 3); fitted logistic regression curves showed that $50 \%$ of third instars with access to Ailanthus reached the fourth instar 2.1 days earlier than those without Ailanthus. In 


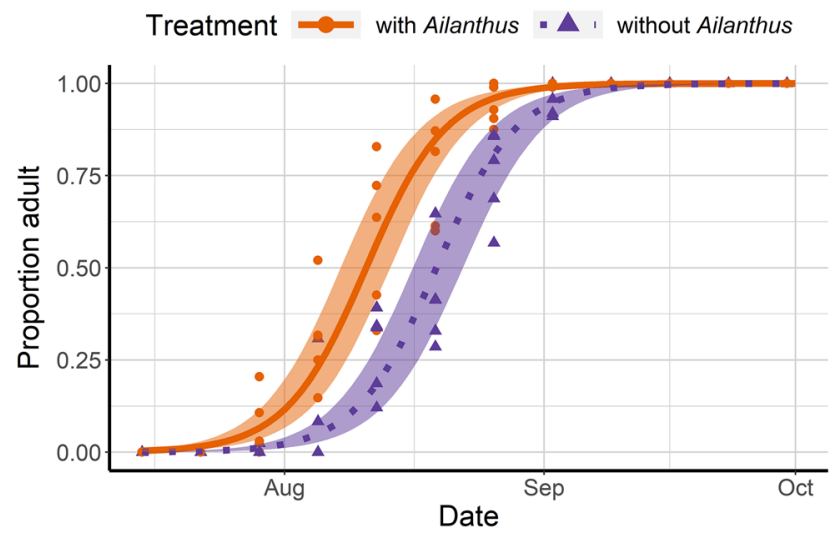

Figure 4. Proportion of $L$. delicatula that emerged as adults over time, with fitted logistic regression lines, for enclosures with and without Ailanthus altissima.

\begin{tabular}{|l|l|r|l|l|l|}
\hline Variable & Source of variation & \multicolumn{1}{|l}{ df } & MS & F-value & $\boldsymbol{P}$-value \\
\hline \multirow{4}{*}{ Third instars } & Tree species & 3 & 3495 & 11.20 & $\mathbf{0 . 0 0 1}$ \\
\cline { 2 - 6 } & Time (week) & 16 & 0.023 & 0.001 & 0.999 \\
\cline { 2 - 6 } & Tree species $\times$ Time & 9 & 388.3 & 1.24 & 0.301 \\
\cline { 2 - 6 } & Error & 59 & & & \\
\hline \multirow{5}{*}{ Fourth instars } & Tree species & 4 & 5218 & 20.68 & $\mathbf{0 . 0 0 1}$ \\
\cline { 2 - 6 } & Time (week) & 5 & 0.067 & 0.011 & 0.967 \\
\cline { 2 - 6 } & Tree species $\times$ Time & 20 & 414.2 & 1.84 & 0.061 \\
\cline { 2 - 6 } & Error & 100 & & & \\
\hline \multirow{5}{*}{ Adults } & Tree species & 3 & 14,347 & 13.45 & $\mathbf{0 . 0 0 1}$ \\
\cline { 2 - 6 } & Time $($ week) & 11 & 1.03 & 0.009 & 0.991 \\
\cline { 2 - 6 } & Tree species $\times$ Time & 33 & 358.9 & 2.98 & 0.063 \\
\cline { 2 - 6 } & Error & 176 & & & \\
\hline
\end{tabular}

Table 1. Repeated measures binomial GLM ANOVA for data on the effect of tree species and time (week) on the proportion of Lycorma delicatula nymphs and adults present on individual trees in cages where they had access to Ailanthus altissima. df, degrees of freedom; MS, mean squares. Statistically significant values are indicated in bold.

cages containing A. altissima $50 \%$ of fourth instars reached adulthood 8.4 days earlier than those in enclosures without $A$. altissima $\left(\chi^{2}=9.67 ; P=0.001\right.$; Fig. 4$)$.

Host plant association of third and fourth instar nymphs as well as adults in A. altissima enclosures were influenced by the available tree species but did not differ over time (Table 1; Fig. 5A-C). In enclosures with $A$. altissima, third instars were most frequently observed on A. altissima (Fig. 5A), while fourth instars were found with equal frequency on A. altissima, S. babylonica and A. saccharinum (Fig. 5B). Adults were mostly observed on A. saccharinum despite the presence of A. altissima (Fig. 5C). In enclosures without A. altissima, host plant association of nymphs and adults differed as a function of tree species but did not differ over time (Table 2; Fig. 6A-C). In enclosures without A. altissima, third instars were most frequently observed on S. babylonica (Fig. 6A), while fourth instars were found with equal frequency on S. babylonica and B. nigra (Fig. 6B). Again, adults were most commonly associated with A. saccharinum (Fig. 6C).

The number of egg masses laid by females was 6.8-fold higher in enclosures with A. altissima ('with Ailanthus': $19.20 \pm 2.13$ (mean \pm SE) than 'without Ailanthus' 2.80 $\pm 0.42 ; U=20.0, P=0.040)$. Egg masses were first observed on September 30, 2020 in the presence of A. altissima and oviposition continued until November 4 when field temperature dropped below $0{ }^{\circ} \mathrm{C}$, killing the remaining adults in both treatments. Oviposition occurred in all five of these enclosures for a total of 96 egg masses. Of these egg masses, 23 were laid on A. altissima, 21 on A. saccharinum, 30 on S. babylonica, 1 on J. nigra, and 14 and 7 on wooden planks and red maple logs placed in the enclosures, respectively. In enclosures without $A$. altissima, 14 egg masses were recorded, with at least one egg mass in each of the 5 enclosures. Oviposition in these cages occurred between October 14 and November 4, 2020. Of these 14 egg masses, one was on B. nigra, 2 on S. babylonica, 6 on A. saccharinum, 2 on planks and 3 on red maple logs. 

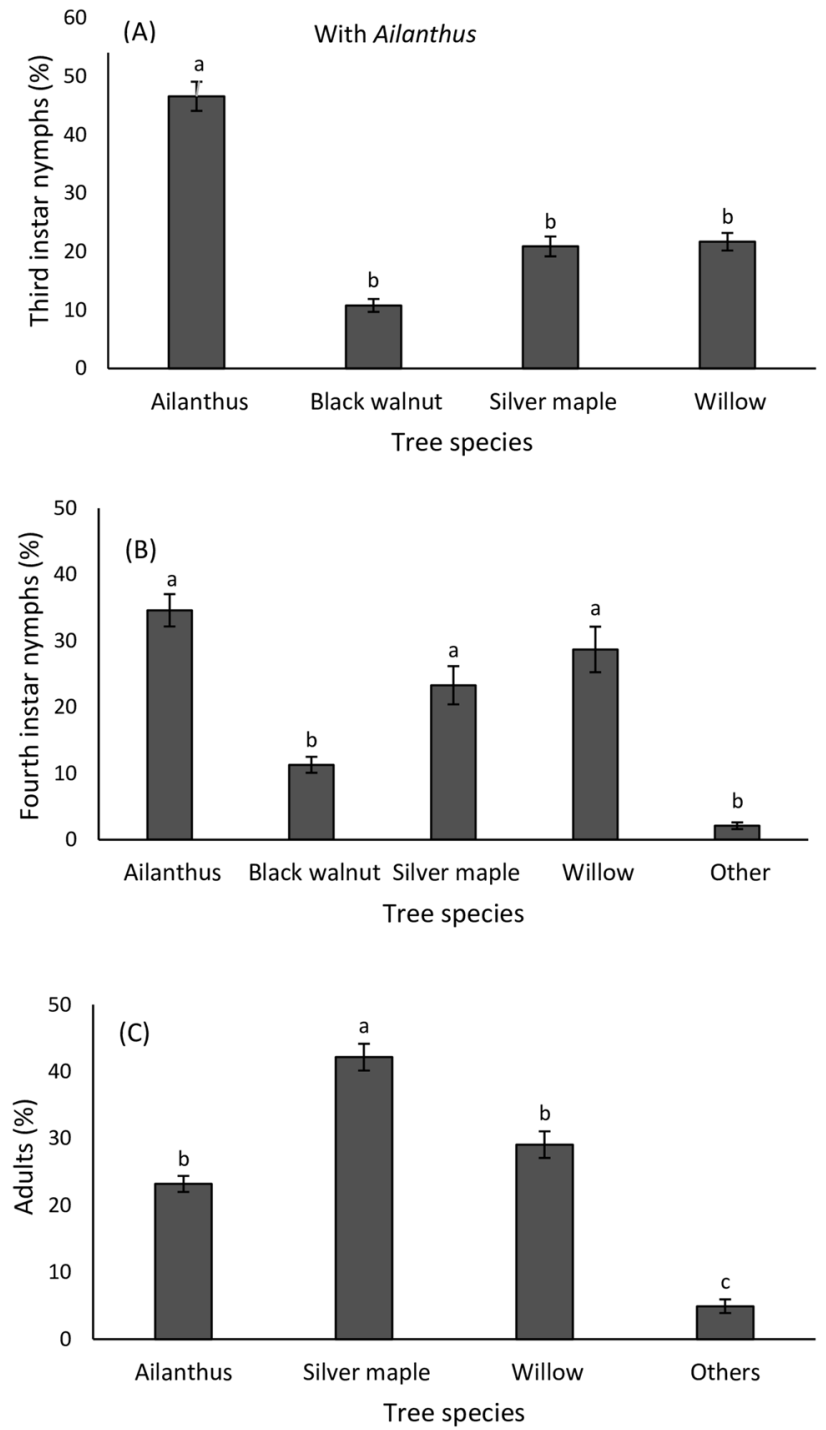

Figure 5. Mean ( \pm SE) proportion of Lycorma delicatula third instars (A) fourth instars (B) and adults (C) present on each tree species in enclosures with Ailanthus (Ailanthus altissima), silver maple (Acer saccharinum), black walnut (Juglans nigra) and willow (Salix babylonica) ( $n=5$ enclosures) from July 15 to November 4, 2020. Nymphs and adults found on annual plants (2\%) within the enclosure or on enclosure walls (98\%) are included as 'Others.' Means within a column followed by different letters are significantly different (Bonferroni post hoc test: $P<0.05)$. No adults were found on black walnut and no third instar nymphs were found on other surfaces.

Offspring performance. After being released in pop-up cages with access to healthy A. altissima, the proportion of hatched offspring from eggs laid the previous fall did not differ as a function of parental diet $\left(\chi^{2}=0.70\right.$, $\mathrm{df}=1, P=0.401$ ). Development time (hatch to adults) also did not differ between offspring from parents with or without access to $A$. altissima $\left(\chi^{2}=0.13, \mathrm{df}=1, P=0.722\right)$.

\section{Discussion}

Lycorma delicatula can complete development and reproduce without access to A. altissima, confirming our findings from the previous year ${ }^{19}$, and providing additional insight into host association of L. delicatula among common woody ornamental trees. Fitness of the insect was greater in the presence of A. altissima. Survival was higher, development time was faster, and the number of egg masses was 6.8 -fold higher than for insects that lacked access to A. altissima. This study also showed that offspring from parents that had been reared without access to A. altissima did not suffer fitness effects into the next generation. We hypothesize that reduced egg mass production in cages without Ailanthus was caused by slower development resulting in a shorter time span between adult emergence and freezing-induced mortality during which adults can mate and lay eggs. However, in southern climates where freezing temperatures appear several months later in the year or not at all, lack of access to A. altissima may have less impact on fitness since there could be time for slower developing adults to continue oviposition into the early winter. 


\begin{tabular}{|l|l|r|l|l|l|}
\hline Variable & Source of variation & \multicolumn{1}{l|}{ df } & MS & F-value & $\boldsymbol{P}$-value \\
\hline \multirow{5}{*}{ Third instars } & Tree species & 3 & 1241 & 10.42 & $\mathbf{0 . 0 0 1}$ \\
\cline { 2 - 6 } & Time (week) & 3 & 0.09 & 0.05 & 0.970 \\
\cline { 2 - 6 } & Tree species $\times$ Time & 9 & 292.3 & 2.45 & 0.057 \\
\cline { 2 - 6 } & Error & 59 & & & \\
\hline \multirow{5}{*}{ Fourth instars } & Tree species & 4 & 4071 & 8.22 & $\mathbf{0 . 0 0 1}$ \\
\cline { 2 - 6 } & Time (week) & 5 & 0.021 & 0.001 & 0.999 \\
\cline { 2 - 6 } & Tree species $\times$ Time & 20 & 342.5 & 1.42 & 0.129 \\
\cline { 2 - 6 } & Error & 100 & & & \\
\hline \multirow{5}{*}{ Adults } & Tree species & 3 & 14,352 & 13.05 & $\mathbf{0 . 0 0 1}$ \\
\cline { 2 - 6 } & Time (week) & 11 & 0.32 & 0.003 & 0.993 \\
\cline { 2 - 6 } & Tree species $\times$ Time & 33 & 3231 & 2.11 & 0.071 \\
\cline { 2 - 6 } & Error & 176 & & & \\
\hline
\end{tabular}

Table 2. Repeated measures binomial GLM ANOVA for analysis of data on the effect of tree species and time (week) on the proportion of Lycorma delicatula nymphs and adults present on individual trees in cages without Ailanthus altissima. df, degrees of freedom; MS, mean squares. Statistically significant values are indicated in bold.

In this study, survival to adult was high for both treatments (with and without Ailanthus), although survival was slightly higher (10\% difference) in the presence of A. altissima. By early September 2020, approximately $63 \%$ of the individuals released (with and without access to Ailanthus) were still alive. This is in contrast to our 2019 study where survival on younger, smaller trees was less than $20 \%$ for both treatments (with and without access to Ailanthus) by September 2 when most lanternflies were adults ${ }^{19}$; however, the previous study started with the release of newly hatched first instars. Lower survival in 2019 could have been due to early mortality of first and second instar nymphs and/or having access to smaller trees in 2019 than in 2020 in that larger and/or more vigorous trees may provide a greater volume of sap and nutrients over time.

The faster development time of $L$. delicatula in enclosures with A. altissima suggests that adults could reach sexual maturity faster in areas where A. altissima is abundant. Development time remains one of the most crucial fitness indicators of host plant nutritional quality and can influence insect survival, behavior and physiology ${ }^{23}$. For example, several studies have found that slow development in phytophagous insects can cause high mortality of immature stages in the field by exposing them to unfavorable environmental conditions for a longer time period $^{24,25}$. A key fitness cost caused by prolonged development in L. delicatula was narrowing of the reproductive window for adults, which was reflected in markedly fewer eggs being laid before freezing temperatures killed the remaining adults ${ }^{19}$.

Third and fourth instar nymphs were mostly associated with A. altissima when it was present, however, more adults were found on A. saccharinum than on A. altissima when both tree species were present. This may occur when the pest has exhausted the ability of A. altissima to provide sufficient sap flow, which also coincides with the onset of senescence of this tree species in mid-September. In the absence of A. altissima, B. nigra, A. saccharinum, J. nigra and S. babylonica together appeared to provide sufficient nutrition for growth and reproduction, but sap flow may be lower in these species, which could explain the delayed development time in the absence of A. altissima. Preferred host trees (A. altissima and $V$. vinifera) with a high sap flow are known to support faster development and increased performance in L. delicatula ${ }^{26-28}$. However, we cannot rule out that if given access to mature and vigorous suitable hosts such as A. saccharinum or A. rubrum, sexual maturity could have occurred at the same rate as those with access to A. altissima. These two maple species are heavily utilized by $L$. delicatula adults in the field in the fall (D.D. Calvin et al. unpublished data). Although the trees in our study were significantly larger than they were the previous year, they were still smaller than trees that are selected by wild populations of L. delicatula adults in the field where profuse feeding is associated with reproductive maturation (pers. observations).

Several factors may influence feeding preference in L. delicatula ranging from host-tree bark characteristics, sap sugar content and flow rate to the presence or absence of defensive chemicals ${ }^{26-28}$. L. delicatula appears to sequester plant defensive chemicals such as alkaloids and quassinoids as a defense against predation, the timing of which may coincide with the onset of aposematic coloration in the fourth instar ${ }^{26}$. Plant architecture may also play a role in host selection; this pest is often observed feeding on hosts with trunks and branches that do not have thick bark. The trees used in our study were chosen because they are frequently infested in the field and do not have the thick bark that occurs on some trees, such as oaks, which are infrequent hosts ${ }^{29}$. L. delicatula has been reported to survive longer on, and prefer, host trees with a high concentration of sap sugars, similar to those produced by A. altissima and $V$. vinifer $a^{28}$. In prior work by Lee and colleagues ${ }^{28}$, the authors reasoned that the improved performance on and preference for A. altissima and V. vinifera is related to high concentrations of sucrose and glucose in A. altissima sap, and high concentrations of sucrose and fructose in V. vinifera sap. Ingestion of sap by fulgorids is passive because they lack a cibarium pump (musculature in the pre-oral cavity that pumps fluids from a food source $)^{17,18,20}$. Several authors have noted that L. delicatula seems to prefer hosts that have high turgor pressure within the phloem vessels, allowing for ingestion of sap at a greater flow rate. 

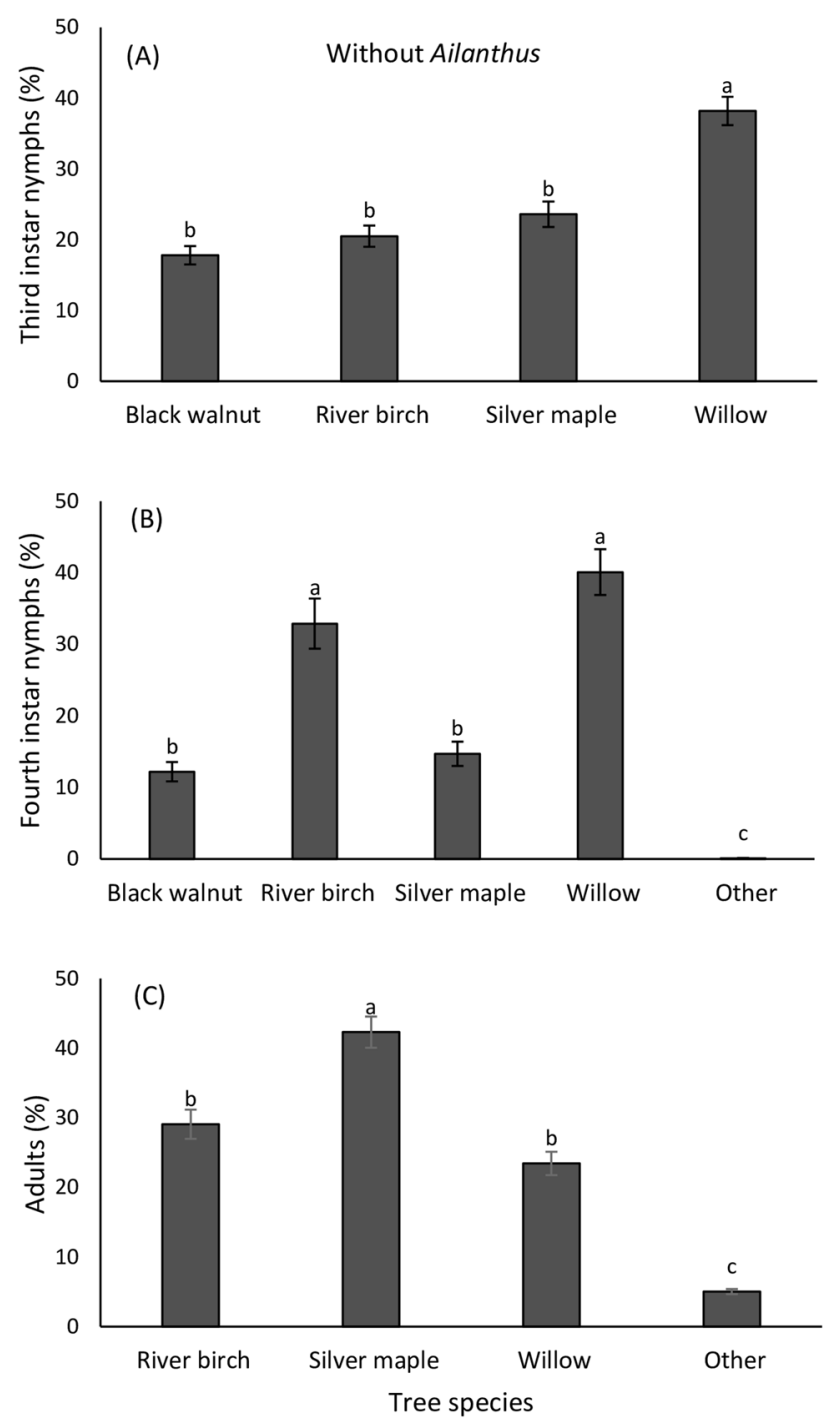

Figure 6. Mean $( \pm \mathrm{SE})$ proportion of Lycorma delicatula third instars (A), fourth instars $(\mathbf{B})$ and adults $(\mathbf{C})$ present on each tree species in enclosures with silver maple (Acer saccharinum), black walnut (Juglans nigra), willow (Salix babylonica) and river birch (Betula nigra) (without Ailanthus altissima, $n=5$ enclosures) from July 15 to November 4, 2020. Nymphs and adults found on other plants (2\%) within the enclosure or on enclosure walls (98\%) are included as 'Others.' Means within a column followed by different letters are significantly different (Bonferroni post hoc test: $P<0.05$ ). No adults were found on black walnut and no third instar nymphs were found on other surfaces.

Although egg masses were laid on all host trees as well as planks and red maple logs, S. babylonica, A. saccharinum, and A. altissima were generally preferred for oviposition. Oviposition substrate selection can be vital to the reproductive success of insect herbivores. The preference-performance hypothesis (a.k.a. mother knows best hypothesis) predicts correlation between oviposition preference by the female parent and host suitability for offspring development ${ }^{30,31}$. However, it does not translate well to species like L. delicatula with immature stages that are highly mobile or instances where the adults and immature life stages feed on different host ${ }^{32}$. Although tree species and branch structure may play a role in the selection of sites for oviposition ${ }^{17}$, why L. delicatula oviposits on non-living materials remains to be explained. The basis for oviposition preferences is not always easy to empirically verify ${ }^{31}$. Some $L$. delicatula researchers think that females lay most of their eggs in the vicinity of where they fed to fatten up and become reproductively mature because it's harder for them to fly once they've gained so much weight ${ }^{33}$. Alternatively, as is evident in some insects and mite species ${ }^{31,34}$, L. delicatula may be following a strategy where females do not necessarily oviposit on suitable hosts to make it harder for predators to find their eggs and early instars.

The ability of L. delicatula to survive, develop and produce egg masses with or without A. altissima may be due to the presence of multiple, suitable host plant species in the enclosures. It is not uncommon for generalist feeders to require diet mixing to acquire the necessary nutrients for development and reproduction ${ }^{35,36}$, and $L$. delicatula appears to demonstrate better fitness when provided multiple suitable host plants. While they can be 
reared from nymphs to adults on a single species such as $V$. vinifera or A. altissima, without diet mixing, adults may not produce eggs. For example, L. delicatula that were reared exclusively on A. altissima or V. vinifera failed to produce egg masses, whereas their counterparts that received a combination of both did (Tracy Leskey, USDA/ ARS, personal communication).

Although L. delicatula developed more slowly without access to A. altissima, the offspring from eggs produced by these adults did not suffer ongoing fitness effects, which could have implications for the spread of this pest in the United States. While range expansion of L. delicatula is likely facilitated by the prevalence of A. altissima, other hardwood tree species can serve as suitable hosts to support development and reproduction. It's possible that in a warmer southern climate, adults that develop more slowly in a region without $A$. altissima may have time to catch up and lay as many egg masses as they would have if there was access to A. altissima. Overall, our findings suggest that managers need to be aware that even in the absence of $A$. altissima in the landscape, several hardwood host trees can be utilized by $L$. delicatula to develop and reproduce.

\section{Data availability}

All relevant data are within the paper.

Received: 6 April 2021; Accepted: 26 July 2021

Published online: 04 August 2021

\section{References}

1. Barringer, L. E., Donovall, L. R., Spichiger, S. E., Lynch, D. \& Henry, D. The first New World record of Lycorma delicatula (Insecta: Hemiptera: Fulgoridae). Entomol. News 125, 20-23 (2015).

2. Dara, S. K., Barringer, L. \& Arthurs, S. P. Lycorma delicatula (Hemiptera: Fulgoridae): A new invasive pest in the United States. J. Integr. Pest Manag. 6, 20 (2015).

3. Jung, J. M., Jung, S., Byeon, D. \& Lee, W. Model-based prediction of potential distribution of the invasive insect pest, spotted lanternfly Lycorma delicatula (Hemiptera: Fulgoridae), by using CLIMEX. J. Asia-Pac. Biodivers. 10, 532-538 (2017).

4. Lee, D.-H., Park, Y.-L. \& Leskey, T. C. A review of biology and management of Lycorma delicatula (Hemiptera: Fulgoridae), an emerging global invasive species. J. Asia-Pac. Entomol. 22, 589-596 (2019).

5. (NYSIPM) New York State Integrated Pest Management. 2020. Spotted lanternfly. https://nysipm.cornell.edu/environment/invas ive-species-exotic-pests/spotted-lanternfly/. Accessed 18 January 2021.

6. Park, M., Kim, S. M. \& Lee, J. H. Genetic structure of Lycorma delicatula (Hemiptera: Fulgoridae) populations in Korea: implication for invasion processes in heterogeneous landscapes. Bull. Entomol. Res. 103, 414-424 (2013).

7. Keller, J. A. et al. Dispersal of Lycorma delicatula (Hemiptera: Fulgoridae) nymphs through contiguous, deciduous forest. Environ. Entomol. 49, 1012-1018 (2020).

8. Smyers, E. C. et al. Spatio-temporal model for predicting spring hatch of the spotted lanternfly (Hemiptera: Fulgoridae). Environ. Entomol. 50, 126-137 (2020).

9. Wakie, T. T., Neven, L. G., Yee, W. L. \& Lu, Z. The establishment risk of Lycorma delicatula (Hemiptera: Fulgoridae) in the United States and globally. J. Econ. Entomol. 113, 306-314 (2019).

10. Urban, J. M. Perspective: shedding light on spotted lanternfly impacts in the USA. Pest Manag. Sci. 76, 10-17 (2020).

11. Harper, J. K., Stone, W., Kelsey, T. W. \& Kime, L. F. Potential Economic Impact of the Spotted Lanternfly on Agriculture and Forestry in Pennsylvania (The Center for Rural Pennsylvania, 2019).

12. Song, M. K. Damage by Lycorma delicatula and chemical control in vineyards. M.S. thesis. Chunbuk National University, Korea (2010).

13. Tedders, W. L. \& Smith, J. S. Shading effect on pecan by sooty mold growth. J. Econ. Entomol. 69, 551-553 (1976).

14. Lemos-Filho, J. P. D. \& Paiva, É. A. S. The effects of sooty mold on photosynthesis and mesophyll structure of mahogany (Swietenia macrophylla King., Meliaceae). Bragantia 65, 11-17 (2006).

15. Han, J. M. et al. Lycorma delicatula (Hemiptera: Auchenorrhyncha: Fulgoridae: Aphaeninae) finally, but suddenly arrived in Korea. Entomol. Res. 38, 281-286 (2008).

16. Park, J. D. et al. Biological characteristics of Lycorma delicatula and the control effects of some insecticides. Korean J. Appl. Entomol. 48, 53-57 (2009).

17. Liu, H. Oviposition substrate selection, egg mass characteristics, host preference, and life history of the spotted lanternfly (Hemiptera: Fulgoridae) in North America. Environ. Entomol. 48, 1452-1468 (2019).

18. Barringer, L. E. \& Ciafré, C. M. Worldwide feeding host plants of spotted lanternfly, with significant additions from North America. Environ. Entomol. 49, 999-1011 (2020).

19. Uyi, O. et al. Spotted lanternfly (Hemiptera: Fulgoridae) can complete development and reproduce without access to the preferred host, Ailanthus altissima. Environ. Entomol. 49, 1185-1190 (2020).

20. Murman, K. Distribution, survival, and development of spotted lanternfly on host plants found in north America. Environ. Entomol. 49, 1270-1281 (2020).

21. Magnusson, A. glmmTMB: Generalized linear mixed models using template model builder. R package v. 0.1.3. https://github.com/ glmmTMB (2017).

22. R Development Core Team. R: A Language and Environment for Statistical Computing Computer Program, Version 3.6.3 (R Development Core Team, 2020).

23. Kariyat, R. R. \& Portman, S. L. Plant-herbivore interactions: Thinking beyond larval growth and mortality. Am. J. Bot. 103, 1-3 (2016).

24. Fordyce, J. A. \& Shapiro, A. M. Another perspective on the slow-growth/high-mortality hypothesis: chilling effects on swallowtail larvae. Ecology 84, 263-268 (2003).

25. Uesugi, A. The slow-growth high-mortality hypothesis: direct experimental support in a leaf mining fly. Ecol. Entomol. 40, 221-228 (2015).

26. Song, S., Kim, S., Kwon, S. W., Lee, S.-I. \& Jablonski, P. G. Defense sequestration associated with narrowing of diet and ontogenetic change to aposematic colours in the spotted lanternfly. Sci. Rep. 8, 16831 (2018).

27. Domingue, M. J. \& Baker, T. C. Orientation of flight for physically disturbed spotted lanternflies, Lycorma delicatula, (Hemiptera, Fulgoridae). J. Asia Pac. Entomol. 22, 117-120 (2019).

28. Lee, J. E. et al. Feeding behavior of Lycorma delicatula (Hemiptera: Fulgoridae) and response on feeding stimulants of some plants. Korean J. Appl. Entomol. 48, 467-477 (2009).

29. Liu, H. Seasonal development, cumulative growing degree-days, and population density of spotted lanternfly (Hemiptera: Fulgoridae) on selected hosts and substrates. Environ. Entomol. 49, 1171-1184 (2020).

30. Jaenike, J. On optimal oviposition behavior in phytophagous insects. Theor. Popul. Biol. 14, 350-356 (1978). 
31. Gripenberg, S., Mayhew, P. J., Parnell, M. \& Roslin, T. A meta-analysis of preference-performance relationships in phytophagous insects. Ecol. Lett. 13, 383-393 (2010).

32. Fujiyama, N., Torii, C., Akabane, M. \& Katakura, H. Oviposition site selection by herbivorous beetles: a comparison of two thistle feeders: Cassida rubiginosa and Henosepilachnniponica. Entomol. Exp. Appl. 128, 41-48 (2008).

33. Wolfin, M. S., Myrick, A. J. \& Baker, T. C. Flight duration capabilities of dispersing adult spotted lanternflies, Lycorma delicatula. J. Insect Behav. 33, 125-137 (2020).

34. Faraji, F., Janssen, A. \& Sabelis, M. W. Oviposition patterns in a predatory mite reduce the risk of egg predation caused by prey. Ecol. Entomol. 27, 660-664 (2002).

35. Behmer, S. T. \& Joern, A. Coexisting generalist herbivores occupy unique nutritional feeding niches. Proc. Natl. Acad. Sci. USA 105, 1977-1982 (2008).

36. Behmer, S. T. Insect herbivore nutrient regulation. Annu. Rev. Entomol. 54, 165-187 (2009).

\section{Acknowledgements}

The authors would like to thank David Long, Anne Johnson, Elizabeth Wagner, Brian Walsh and Scott Alan Swackhamer for assistance during the field study. Funding was provided by Cooperative Agreements with USDA Forest Service Forest Health Protection (Grant 18-CA-11420004-198) and USDA APHIS (Award No: AP19PPQS\&T00C080) and grants from the USDA NIFA and McIntire-Stennis Appropriations under Project \#PEN04684 and Accession \#1018126, the Pennsylvania Department of Agriculture (Grant No. 44187340), and the Horticultural Research Institute. This work was also supported in part by the USDA National Institute of Food and Agriculture and Hatch Appropriations under Project \#PEN04728 and Accession \#1021211.

\section{Author contributions}

K.H. and O.U. conceptualized and designed the study; O.U. performed the field experiments with assistance from E.S.; O.U. and J.K. performed the statistical analysis; O.U. wrote the manuscript; K.H. and J.K. critically reviewed and amended the manuscript.

\section{Competing interests}

The authors declare no competing interests.

\section{Additional information}

Correspondence and requests for materials should be addressed to K.H.

Reprints and permissions information is available at www.nature.com/reprints.

Publisher's note Springer Nature remains neutral with regard to jurisdictional claims in published maps and institutional affiliations.

(c) (i) Open Access This article is licensed under a Creative Commons Attribution 4.0 International License, which permits use, sharing, adaptation, distribution and reproduction in any medium or format, as long as you give appropriate credit to the original author(s) and the source, provide a link to the Creative Commons licence, and indicate if changes were made. The images or other third party material in this article are included in the article's Creative Commons licence, unless indicated otherwise in a credit line to the material. If material is not included in the article's Creative Commons licence and your intended use is not permitted by statutory regulation or exceeds the permitted use, you will need to obtain permission directly from the copyright holder. To view a copy of this licence, visit http://creativecommons.org/licenses/by/4.0/.

(C) The Author(s) 2021 